HAS THE IPCC EXAGGERATED ADVERSE IMPACT OF GLOBAL WARMING ON HUMAN SOCIETIES?

$$
\text { by }
$$

Madhav L Khandekar

\author{
Reprinted from \\ ENERGY \& \\ ENVIRONMENT \\ VOLUME 19 No. 52008
}




\title{
HAS THE IPCC EXAGGERATED ADVERSE IMPACT OF GLOBAL WARMING ON HUMAN SOCIETIES?
}

\author{
Madhav L Khandekar ${ }^{1}$ \\ Environmental Consultant Unionville Ontario CANADA
}

\section{INTRODUCTION}

Has the IPCC exaggerated adverse impact of Global Warming on human societies?

Yes, Certainly! Let me explain: While reviewing the IPCC WGII (Working Group II) Chapter "Assessment of observed changes and responses in natural and managed systems" (Chpt.1, WGII IPCC, 2007) as an external reviewer, I felt time and time again that there were areas where the chapter authors highlighted adverse impact of GW (Global Warming) on human societies, while downplaying possible beneficial impacts. The IPCC authors referred to several publications which projected adverse impacts while ignoring many excellent studies which have questioned these projections. Throughout the text of this important chapter of WGII, there were many instances where adverse impact was highlighted or exaggerated, while possible beneficial impacts were totally ignored. Further, IPCC authors while assessing observed changes in natural systems chose to highlight only those changes which support the GW hypothesis while completely ignoring other observed changes which did not conform to the human-induced GW hypothesis and change. Such cherrypicking of observed climate change to bolster claims of human-caused GW and climate change is disingenuous and does not help understand the real cause of how and why the earth's climate has changed in historical and geological times.

A detailed reading of the Chapter left me with an impression that the deleterious impact of GW on human societies was so imminent and overwhelming that unless something is done right away (to curb the warming), human societies world over are about to perish!

The following section provides selected examples (from Ch 1 WGII) of exaggerated claims made by the IPCC authors:

\footnotetext{
${ }^{1}$ Dr Madhav L Khandekar is a former Research Scientist from Environment Canada and is presently on the editorial board of the Journal Natural Hazards ( Kluwer, Netherlands). Khandekar has been in the fields of weather \& climate for over fifty years and has published over 120 papers, reports, book reviews etc. While at Environment Canada, Khandekar wrote a monograph on ocean surface wave analysis and modeling which has been published by Springer-Verlag in 1989. Khandekar is an External Reviewer for the IPCC 2007 Climate Change Documents.

Address for correspondence: 52 Montrose Crescent, Unionville, Ontario, Canada, L3R 7Z5: mkhandekar@rogers.com
} 


\section{SELECTED EXAMPLES}

1. Executive Summary: Here the GW impacts are listed under several categories, in each a deleterious impact is prominently spelled out. Examples: increasing droughts and flash floods, widespread coastal erosion, cryospheric changes and resulting glacial floods, increased run-off in snow \& glacial basins, lower crop yields due to warming with an example for the Sahel region (Africa) due to reduction in decadal scale precipitation, impact on human health (cholera etc) related to El Nino-Southern Oscillation incidences, increased vector-borne diseases and some water-borne diseases, increasing global catastrophes and significant increases in the values of exposure at risk.

2. Observed Changes in systems \& Sectors: Here examples given are: cryospheric reduction world-wide and rapid glacier melts in South America, escalating sea-level rise, the European heat wave of summer 2003, increase in world-wide drought areas and possibly in flood areas as well, changes in coastal processes due to escalating sea-level rise.

3. Terrestrial \& Biological Systems: changes in phenology (seasonal activities of animals and plants) and their northward migration in Europe.

4. Agriculture \& Forestry: The overall discussion emphasizes reduction in crops and yields due to warming with specific example of Sahel region; increased risk of forest fire activity with increasing temperature.

5. Human Health: Here an increased possibility of outbreak of malaria with examples from East Africa ( Kenya) and South Asia, water-borne disease like cholera in South Asia and other ENSO (El Nino-Southern Oscillation) related health impacts in Asia are highlighted.

6. Disasters \& Hazards: A general theme here is " increase in catastrophic events like floods, droughts, heat waves etc and related economic losses worldwide which are all directly related to warming of the earth's surface temperature'. As supporting evidence, a couple of unpublished documents are cited, while several published studies refuting such increases are ignored.

\section{A REALITY CHECK WITH OBSERVATIONS} AND PEER-REVIEWED STUDIES

It is imperative to analyze various claims made above in the context of the reality of climate as it continues to evolve in different regions of the earth. It is also important to carefully assess all available literature and observed data to determine if the present climate does indeed follow the "Global Warming" path as projected by the IPCC scientists and the climate model projections.

The Executive Summary for Chapter 1 uses terms like "increase in floods, flash floods etc" which are very general in nature and do not appear to have been thoroughly analyzed to determine if there is indeed a 'human influence' in such events. Several peer-reviewed studies published in recent literature document an increase in extreme weather (EW) however, a close analysis reveals that such 'increase' is more a perception than reality. In a report prepared for the Government of Alberta in western Canada (Khandekar 2002), I have examined typical EW events like thunderstorms, 
tornadoes, floods, droughts, heat waves for the Canadian Prairie provinces and concluded that none of the EW events showed any increase in recent years. I have also examined such EW events elsewhere (Khandekar et al, 2005) and the general conclusion was that these events did not show any systematic increase/decrease in recent years. As synthesized by Khandekar et al (2005) "the link between $G W$ \& EW is more a perception than reality, this perception being fostered as a result of increased awareness and media attention to such weather events". Additional discussion on EW will be presented in a later section.

A reality check for some of the items listed earlier is presented below:

1. Cryospheric Reduction: Glacier retreat and advances are part of natural variability and not a direct consequence of GW as IPCC authors seem to imply in their assessment. The authors have avoided referring to many studies readily available in peer-reviewed literature while emphasizing studies which purportedly show 'rapid' shrinking of world-wide glaciers and associated sealevel rise. One of the most talked about examples is the "vanishing ice cap on Mt Kilimanjaro' in equatorial Africa. This melting has been going on for well over a hundred years now as documented in a paper by Kaser et al (2004). The paper by Kaser et al discounts any GW impact and suggests a drastic drop in atmospheric moisture at the end of the $19^{\text {th }}$ century and the ensuing drier climate as possible reasons for the declining ice cap. Ironically however, the authors of Ch1 did not refer to this important paper as well as several other papers on the glaciers in the Swiss Alps and elsewhere (e.g., Hormes et al 2001, 2006). A few other papers suggest glacier shrinking to solar variability during the Holocene in particular. The issue of glacier retreat and advance is much more complex than what IPCC authors have presented in their simplistic treatment using the GW hypothesis.

2. The European summer 2003 heat wave: The heat wave in Europe during June-July of 2003 was an exceptional event and received wide publicity because of a large number of fatalities due to dehydration and heat stress which affected several thousand elderly people in France and elsewhere in Western Europe. Although an exceptional weather event, the 2003 European heat wave was by no means unprecedented and was a result of a persistent upper-level ridge of high pressure over the Continent (see AMS Bulletin, June 2004). Linking the 2003 heat wave in Europe to human activity is unconvincing and without any merit. Such heat waves have occurred in the past in various parts of the earth and have been triggered by various reasons, most commonly due to an anomalous but not uncommon atmospheric flow pattern. What is of interest here is that just six months earlier, the winter months of December 2002 and January 2003 were unusually cold in many parts of North America, Europe and this unusually cold winter was felt even in the tropical latitudes of Vietnam and Bangladesh where several hundred people died of long exposure to significantly below normal temperatures. The winter season of 2002/03 over Northern Hemisphere was much more wide-spread globally than the 
European heat wave of summer 2003. The IPCC authors highlighted the European heat wave as an example of human activity induced EW event, but completely ignored the unusually cold winter season of 2002/03. Also the summer (June/July/August) of 2004 was one of the coldest over most of North America. These and many other recent climate anomalies of cold as well as warm season are most certainly due to natural climate variability and are in no way associated with human activity.

3. Changes in phenology: Most studies cited in this area are almost exclusively for Europe where considerable research efforts have documented changes in bird and vegetation migration in the last few years. However a significant lack of such studies from other regions of the world makes it difficult to draw any conclusion about climate change link to this 'northward' migration. The IPCC authors do not provide any explanation for lack of studies in other regions while concluding climate change impact on (global-scale) phenology.

4. Impact on Agriculture: The IPCC authors imply a deleterious impact of GW warming on agriculture by providing an example of Sahel region where recurring droughts have reduced peanut crop yield in recent years. The IPCC authors completely ignore increased agriculture yields in other grain producing regions (India, Canada, USA, Australia) where the mean temperature has warmed by about $1 \mathrm{C}$ in the last fifty years, however grain yields have not declined at all. In India, improved farming and irrigation technology has resulted in four to five fold increases in rice and wheat yield since 1950 (see Selvaraju 2003). Similar increase in grain yield has been recorded in other grain producing countries which IPCC authors have completely ignored. The IPCC authors also ignore the beneficial impacts of increasing concentrations of carbon dioxide on world-wide forestry. Recent satellite data show convincingly that the world forests have been enriched due to increasing concentration of carbon dioxide and this has helped increase the "greening" of the earth's surface.

5. Disasters \& Hazards: The IPCC continues with its theme of "increased catastrophes world-wide leading to increased economic losses". The evidence for increased economic losses is presented using an obscure unpublished study (Miller et al 2006) while several peer-reviewed studies, notably by the highly respected US climatologist Stanley Changnon are completely ignored. Changnon and his associates have amply documented that the Shifting Economic Impacts from Weather Extremes is a Result of Societal Change, Not Global Warming (Chagnon 2003, Chagnon et al 2001). Using unpublished work to bolster claims of escalating economic costs while ignoring peerreviewed studies which document otherwise is an unacceptable and unscientific practice.

6. Human Health: The IPCC raises the specter of malaria becoming more prevalent in a warmer future climate. The IPCC also refers to possible increase in cholera and other ENSO related health impacts in south Asia, in particular. Several studies by Dr Paul Reiter, an expert epidemiologist at the Pasteur Institute in Paris (e.g., Reiter 2001) demonstrate that the mosquito-borne 
diseases like malaria and dengue fever were prevalent in Europe and elsewhere even during the Little Ice Age. Reiter further demonstrates that the control of malaria and dengue is determined by human activity, ecology and vector biology and there is no simple relationship to changing climate or to GW. The IPCC reference to cholera and other ENSO related health impacts in south Asia is a normal occurrence during the Asian Monsoon season and has no relation to $\mathrm{GW}$ or climate change.

\section{EXTREME WEATHER, SEA-LEVEL RISE AND OTHER ISSUES}

Extreme Weather (EW) and Sea-level Rise (SLR) are two of the most contentious issues in the present debate on GW impact. The IPCC Documents and climate models project increasing EW events and an escalating SLR as the earth's mean temperature rises in future. As mentioned earlier, the EW/GW link is more a perception than reality, primarily due to increased media attention. Many EW events of the past have remained unnoticed and unreported due to lack of observing technology and/or due to lack of interest in these events at the time. The recent media hype about EW events has provided a new spin to these events as the harbinger of future climate! Ironically, some of the winter season EW events are also being linked with GW impact which neither the IPCC nor the climate models project as possible GW impact. The recent statement on EW put out by the WMO (World Meteorological Organization, Geneva) includes some winter weather extremes of the Southern Hemisphere $(\mathrm{SH})$. Two noteworthy winter weather extremes from the $\mathrm{SH}$ this year are: 1. several centimeters of snow in Buenos Aires (Argentina) on July 7, 2007, followed by a shivering temperature of $-22 \mathrm{C}$ ! The last time it snowed in Buenos Aires was in 1918! 2. On 27 June 2007, a cold front moved across South Africa bringing the country's first significant snowfall since 1981 (25 $\mathrm{cm}$ in parts of the country). Many other winter weather extremes have been reported in recent years (see Khandekar 2003, 2004). Interestingly, none of the climate models offer any explanation for the increasing frequency of winter weather extremes in recent years.

The SLR and its estimate for the next one hundred years has been a subject of several dozen studies in recent years. Many of these studies assume significant melting of the Arctic and Antarctic ice shelves (principally Greenland and West Antarctic ice sheets) during the next 50 to 100 years and this melt-down could produce an escalated SLR with values as high as 1 to 2 meters (or more) over the next 100 years. There are several uncertainties in these estimates and the possibility of significant melt-down of Arctic \& Antarctic Ice Sheets remains far from certain. Other recent papers now seem to suggest that the SLR due to melting of mountain glaciers and ice caps (outside of Arctic \& Antarctic) will only be about $5 \mathrm{~cm}$ over next 100 years, just half the earlier estimate. Another recent paper (Holgate 2007) documents that the SLR during the first half of the $20^{\text {th }}$ century was higher than the latter half of the century, thus discounting any suggestion about 'escalating SLR at present'.

For many countries in the higher latitudes of both the Hemispheres, the present climate change (milder winters, reduced house-heating cost, longer agricultural season) can be beneficial in general. The IPCC scientists have completely missed this aspect of climate change. 


\section{CONCLUDING REMARKS}

The exaggerated claim of GW impacts by the IPCC has led to a distortion of the reality of climate change and its future impact. The earth's climate has changed and is changing continuously, a fact accepted by most climate scientists on both sides of the present debate. Is the present climate change deleterious to human societies? Are there beneficial aspects of climate change that have been overlooked? Do adverse impacts outweigh beneficial impacts? We do not have all the answers yet.

There is a definite need to carefully analyze climate change impact on world-wide human societies. The IPCC assessment is far from objective and needs to be critically re-assessed.

\section{ACKNOWLEDGEMENTS}

I wish to express my sincere appreciation to Benny Peiser for encouraging me to prepare this article.

\section{REFERENCES}

AMS Bulletin 2004: Annual Climate Review 2003, p. S1-S72, Bulletin American Meteorological Society June 2003.

Changnon S A et al 2000: Trends in socio-economic impacts related to weather \& climate extremes in the USA. Bulletin, American Meteorological Society, 81, 437-442.

Changnon S A 2003: Shifting economic impacts from weather extremes in the United States: A result of societal change, not global warming. Natural Hazards 29, June 2003, 273-290.

Holgate S J 2007: On the decadal rates of sea level change during the twentieth century. Geophysical Research Letters, 34 L01602, doi:10.1029/2006GL028492.

Hormes A. et al 2001: The Alps with little ice: evidence for eight Holocene phases of reduced glacier extent in the central Swiss Alps. The Holocene, 11, 255-265.

Holmes A. et al 2006: A geochronological approach to understanding the role of solar activity on Holocene glacier length variability in the Swiss Alps. Geogra. Ann. 88A(4), 281-294(Swedish Society for Anthropology \& Geography).

Khandekar M L 2002: Trends and changes in extreme weather events: An assessment with a focus on Alberta and Canadian Prairies. Report prepared for Alberta Environment (Canada), October 2002, ISBN 0-7785-2428-0, p.56.

Khandekar M L 2003: Comments on WMO statement on extreme weather events. EOS, V 84, No. 41, 14 October 2003( FORUM).

Khandekar M L 2004: Are climate model projections reliable enough for climate policy? Energy \& Environment 15 521-525.

Khandekar M L et al 2005: The global warming debate: A review of the state of science. Pure \& Applied Geophysics 162 1557-1586.

Miller S et al 2006: Weather related catastrophe loss trends and the impact of climate change. To be published ( to be circulated prior to publication) [comment: This is all the info available on this study. I find it incredible that the IPCC authors would use this obscure unpublished study 
to bolster claims of increased economic losses while ignoring other available studies which refute such claim].

Reiter Paul 2001: Climate change and mosquito-borne disease. Environmental Health Perspectives, 109, 141-161.

Selvaraju R 2003: Impact of El Nino-Southern Oscillation on Indian food-grain production. Int'l J of Climatology 23 187-206. 
